\title{
The Differential Impact of Bulk Text Message Advertising on Consumer Attention
}

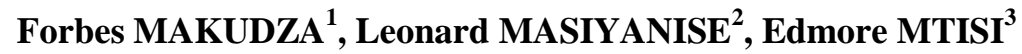 \\ Received: May 23, 2020. Revised: June 28, 2020. Accepted: July 05, 2020
}

\begin{abstract}
Purpose: The purpose of this study was to identify factors that enhance the effectiveness of bulk text message advertising on consumer attention in the telecommunications industry in Zimbabwe. Research design, data and methodology: The study collected data using structured questionnaires. The study attracted 293 responses from consumer subscribers of the Zimbabwean telecommunications industry. Data was analysed using SPSS and measures of association, direction, strength and significance were used. Results: The study found out that the examined variables of bulk text messaging (Simplicity, Frequency and Informativeness) had a positive significant impact on consumers' attention $(\beta=0.645$; p-value $<0.05)$. The study examined four bulk text advertising determinants, namely frequency, simplicity, informativeness and credibility. Only credibility was found to be statistically insignificant ( $p$-value $>0.05)$, whilst frequency had an inverse effect on consumer attention. Simplicity of bulk text advertisements recorded a high positive and significant impact whilst informativeness was also positively, and significantly affecting consumer attention. Conclusions: The study concluded that for bulk text advertising to be effective, text messages should be informative, easy to understand and dispatched less frequently. It was further concluded that bulk text advertising should follow permission marketing where consumers consent before hand to be recipients of commercials.
\end{abstract}

Keywords : Marketing, Bulk text message adverstising, Consumer attention, SMS advertising

JEL Classification Code: M31, M37, C12, C21

\section{Introduction}

This article investigates the antecedents of effective bulk text message advertising and their effect on consumer attention. There has been an increase in the usage of bulk short message services (SMS) in advertising as a result of

1 Corresponding Author. PhD Candidate, Lecturer, Business Management Department, Faculty of Agribusiness and Commerce, Manicaland State University of Applied Sciences, Zimbabwe. Email: forbesmakudza@gmail.com

2 Researcher, Department of Finance, Birmingham University, U.K, Email: leonardmasiyanise@gmail.com

3 Researcher, Department of Strategic Management, Faculty of Commerce, Great Zimbabwe University. Zimbabwe.

Email: edmoremtisi45@gmail.com

(c) Copyright: The Author(s)

This is an Open Access article distributed under the terms of the Creative Commons Attribution Non-Commercial License (https://creativecommons.org/licenses/by-nc/4.0/) which permits unrestricted non-commercial use, distribution, and reproduction in any medium, provided the original work is properly cited. the proliferation of mobile phones. For instance, in year 2000 there were 2.13 mobile subscriptions per 100 inhabitants yet the number rose to 83.18 in 2016 (Gondoiri, 2018).

Bulk SMS advertising has been more pronounced in Zimbabwe, Africa, because of the low proliferation rates of smartphones (Bomiegha \& Ezema, 2017). With a low adoption rate of smartphones, bulk text message advertising becomes more ideal to reach consumers on a one-on-one basis because anyone who owns a mobile phone can receive an SMS.

Regardless of the extensive usage of bulk text advertising, there has never been a systematic study in Zimbabwe to analyse the effectiveness of such an advertising channel. The existing studies on a global scale were predominantly descriptive of bulk text messaging, but failed to explain the factors that enhance the effectiveness of bulk text advertising (Oguntomisin \& Oladipo, 2017). This article therefore bridges the gap by analysing the factors that 
promote effective use of bulk SMSs as a channel of marketing.

This paper also presents a new orientation to measure the effectiveness of bulk text advertising on consumer attention. This is because consumer attention is the driving force to all positive consumer behavioural actions. Without consumers' attention, advertising efforts are lost through perceptual blocking and selective distortion. This approach was informed by several contemporary and classical studies (Ajzen \& Fishbein, 1983; Dickinger \& Haghirian, 2004; Oh \& Lee, 2020; Teixeira, 2014).

Some factors which justify the need for this study included the role of the consumer in SMS advertising. Text message advertising borders on the concept of permission marketing (opt in) which follows that customers should consent to receiving messages from a company or business agent (Godin, 2004; Oh \& Lee, 2020). This however has never been the case in Zimbabwe, where the three companies in the mobile telecommunications, Econet Wireless, Telecel and Netone, take turns to win the race of sending bulk unsolicited text messages to their humble customers without their consent.

On average, customers receive 5 SMS advertisements per day from players in the telecommunications in Zimbabwe, and the rate can be more when telecommunication companies introduce a promotion which should be promoted using text messaging (Chaparadza, 2018; Pikirayi, 2017). The intensity and frequency of bulk text advertising in Zimbabwe has been rampant. Pikirayi (2017) suggests that each time a subscriber hears an SMS tone; it is always almost true that the message is an uninvited guest from the telecommunication players. This implies the need for a framework which improves the acceptance of bulk text message advertising by consumers.

Using previous theoretical results, the study therefore modeled a framework with four bulk text messaging determinants which influence consumers' attention. These determinants are: simplicity, frequency, informativeness and credibility. An examination of these determinants of effective bulk SMS advertising was thus measured against consumer attention using a quantitative methodological approach in Zimbabwe.

\section{Literature Review}

\subsection{Bulk SMS Advertising}

Bulk SMS (BSMS) advertising refers to spontaneous text messages which are sent in bulk for commercial or other purposes, and indiscriminately to unsuspecting subscribers (Bomiegha \& Ezema, 2017). If not well managed, bulk unsolicited messages violate consumers' privacy (Ngwero,
2019). Due to the personal nature of mobile devices, SMS adverts coming in will always draw the attention of the user, who is forced to open such messages, thereby intruding into such user's privacy (Strom, Vendel, \& Bredican, 2014).

In line with Bomiegha and Ezema (2017), bulk SMS advertising can also be called spam SMS or unsolicited SMS because of their unwanted gestures. Spam short messages have similar features with spam emails: they are unsolicited for by the receiver, sent for commercial or financial purposes, and are sent indiscriminately in bulk form.

SMS advertising allows sending of text messages via the network operators' message centers available on mobile handsets, or they can be sent from other networks using the SMS gateway websites (Afzal, Paras, \& Gangwani, 2015). SMS is considered as an almost instantaneous communication medium because SMS operators make use of a 'store-and-forward' packet switching concept which means that even if the recipients' mobile phone is switched off, the users can still receive the message on their phone when they switch on their mobile (Lai, 2014; Ryu, 2019).

According to Afzal, Paras and Gangwani (2015) SMSs work in almost all parts of world as they are part of the Global System for Mobile (GSM) communication digital mobile standard. Malikula (2020) contributes that an SMS is based on alphanumeric characters of up to 160 characters. Lai (2014) adds to that knowledge that SMSs provide other various value-added services as well such as stock alerts, sports updates, entertainment services, news delivery, ring tones downloading and electronic commerce authentication. Mobile advertisements are more individualistic and thus require personalization (Choi, Liu, \& Li, 2018; Hidayat, Pabuayon, \& Muawanah, 2020). Bulk SMSs also provide for a close intimate relationship between an organisation and its customers (Bhandari \& Bansal, 2018). Since the usage of bulk text messaging requires the adoption of mobile technologies, Lakhwani, Dastane, Satar, and Johari (2020) opine that the move is more likely to lead to organisational performance.

\subsection{Consumer Attention}

Consumer attention is a necessary consumer behaviour ingredient for effective SMS advertising. According to Teixeira (2014), the market for consumer attention has become so competitive that attention can be regarded as a currency. The rising cost of this ingredient in the marketplace is causing marketers to waste money on costly attention sources or reduce their investment in promoting their brands. Dickinger and Haghirian (2004) also see attention as a key aspect of SMS advertising. Without adequate attention, subscribers may forget a mobile advert, ignore it, or skip it altogether, however, gaining attention helps initiate positive consumer behaviors (Dickinger \& 
Haghirian, 2004).

Teixeira (2014) expresses attention as the allocation of mental resources, visual or cognitive, to visible or conceptual objects. Before consumers can be affected by advertising messages, they need to pay attention first. Without attention, all advertising efforts will be lost. The same thought was shared by Strom, Vendel, and Bredican (2014) that what influences the consumers' buying process is attention, which will then translate into other action oriented results such as interest, intention to buy and actual purchase.

Consumers often do not deliberately pay attention to advertisements, and it is impossible to process all advertisement messages that are received (Haan \& MoragaGonzalez, 2011). However, the more often consumers are exposed to an advertisement, the more likely that they remember it, and the more likely that they act upon it.

To that end, Mulilima (2020) suggest that when companies are advertising using SMSs, it is important to have a series of SMSs that speak the same marketing commercial. That basically means sending more than one SMS to the same consumer. Likening that to outdoor advertising, Haan and Moraga-Gonzalez (2011) suggest that the more a consumer is exposed to a company's commercial, the more chances that the consumer will buy-in his attention. Once attention is found, all other aspects of consumer usage will follow.

Angtha and Gastha (2015) disagree on the need for repetitive action to grab the attention of the customer using SMSs. They thought that in the mobile marketing business, there is no much need to repeat the same message over and over again. Their reasons border on the fact that SMSs are usually kept in the phone of customers so subscribers can revisit them should they need clarity.

The views of Angtha and Gastha (2015) were shared by Johnson (2014) who also believed that there is no need for over emphasis if marketers are using SMS medium. Johnson (2014) further posits that if SMSs are unsolicited and they keep coming, the consumers may decide not to open them completely leading to a total eclipse on consumer attention.

The challenge of consumer attention in SMS advertising is gradually rising. Ngwero (2019) notices that the advent of new products daily and the need for marketers to get the products known by the customers create an over flask of bulk SMS to subscribers.

Schiffman and Kanuk (2008) identified two factors that act as antecedents of consumers' perception of attention in advertisements, namely selective attention and selective distortion. Selective attention is the process of reacting to certain stimuli selectively when several occur simultaneously. It is the process of selecting some inputs to attend to while ignoring others. (Schiffman \& Kanuk, 2008). A text message advert is more likely to selectively gain subscriber attention if it relates to an anticipated event.

When subscribers of mobile phones are not interested in SMSs that companies throw on them, Schiffman and Kanuk (2008) suggest that it leads to selective distortion. Selective distortion refers to an individual blocking the incoming message or information.

\subsection{Determinants of Effective Bulk SMS Advertising}

Several ideas were put forward to address the "what" question of an SMS advertisement. Ideally, the dilemma of mobile marketing advertisers is to know what should contain the SMS, how long should it be and how frequent should it be sent to the subscribers (Karlsson, 2017).

Brackett and Carr (2011) carried out a study to ascertain the role of SMS advertising. In their study, they identified four SMS advertising constructs namely informativeness, entertainment, irritation and credibility. Following the study by Brackett and Carr (2011), Tsang (2014) carried out a study using the same SMS constructs used by Brackett and Carr (2011). The later study therefore verified the effect of perceived informativeness, entertainment, irritation and credibility on consumers' attitudes towards mobile advertising. Tsang (2014)'s study revealed that informativeness and credibility, rather than entertainment and irritation, affect attitudes of consumers towards mobile advertising.

Using the same constructs, David (2016) conducted a similar study but using a different target group. David (2016) used China as his target group but the essence of the study was maintained; to identify the effect of SMS informativeness, credibility, entertainment, irritation, and personalization on consumer attitudes toward SMS advertising. David (2016)'s study found out that Irritation had no statistical association with SMS advertising. Jong and Lee (2017) also investigated the effect of SMS advertising on consumer behaviour. It appears that they built their model on the same constructs of Brackett and Carr (2011). Their findings were rather radical to the previous studies as they found little association in most variables. They then proposed seven factors that may affect consumer behaviour towards SMS advertising. However, only convenience and multimedia service showed a significant effect in their empirical study.

Tsang (2014) carried out a related study to identify the role of SMS advertisements on consumer attitude. They found out that simple, fun and informative SMS advertisements from a credible sender have positive impact on consumer attitudes. On the other hand, irritating content of the advertisement would yield a negative impact. Enpocket (2016) notes that consumers generally perceive advertisement messages aimed at their self-needs in a better 
way. Though his SMS constructs were not clearly stated as informativeness and entertainment, his results showed that consumers tent to enjoy messages that they regard as useful.

Drossos, Giaglis, Lekakos, Kokkinaki, and Stavraki (2014) also studied SMS content. In their study, they sampled a group of university students and found out that SMSs that are simple to understand, that are short in size and are written in the simplest terms were more attractive than those with deep words. If fairly executed, mobile advertising will not only grab user attention but can also contribute to customer satisfaction (Cho, Potluri, \& Youn, 2020)

Analysis of literature has revealed that several determinants of bulk SMS were studied before by many scholars (Brackett \& Carr, 2011; David, 2016; Drossos et al., 2014; Enpocket, 2016; Lee, 2017; Tsang, 2014). However, their main goal was to identify significant determinants without focusing on a sequential relationship with consumer attention. This was because their advertising effectiveness was measured based on organisational indicators, yet the end result should be the effect the SMS advertisement has on consumers' purchase intention. In addition, literature does not synthesize the determinants of effective bulk SMS advertising. For instance, Ngwero (2019) highlighted over ten determinants of text advertising. Researchers introduced their own determinants and the unification of these determinants was lacking.

The current study therefore closed the gap by synthesising and unifying the previously introduced determinants of bulk text advertising into four. The study closely analysed the determinants that were tested over time and synthesized the determinants that had a significant effect. To that end, the following bulk SMS advertising determinants were considered: simplicity, frequency, informativeness and credibility.

\subsubsection{Simplicity}

Simplicity of SMS advertisements refers to the subscribers' perception of how easy and straightforward the SMS commercial is. It goes on to also look at the grammatical correctness. A good SMS should be written in simple terms and language which is easy for the majority to understand. That is particularly important since SMS advertising is a one-to-many channel which targets the mainstream (Afzal et al., 2015).

According to Oguntomisin and Oladipo (2017) when SMS adverts are not easy to understand, subscribers would shun anything that would want to take them back into a classroom setting for it to be understood. The communication should be simple and in plain language. The language used in the SMS should appeal to both the old and the young, as well as to all gender variations (Oguntomisin \& Oladipo, 2017). Byun and Kyung (2020) also concluded that for mobile marketing to be acceptable, it has to be ease to use.

Another element of simplicity raised by Amin (2014) is the size of the message. Generally, an SMS has a maximum of 160 characters. Amin (2014) suggests that marketers should not get carried away by the need to raise all 160 characters. The same was noted by Lim (2019) that twentyfirst century customers are ever busy and dynamic, therefore SMSs should be kept short simple and to the point. That would make it easy for subscribers to read through and follow. For mobile technologies to be adopted, perceived ease of use is an antecedent factor (Ambarwati, Astuti, \& Dijaya, 2020; Lee, 2020; Le, Ngo, Trinh, \& Nguyen, 2020; Nguyen, 2020).

SMS advertisements are simple if they are easy to understand, have language which is easy to read, are short, enjoyable and without grammatical errors (Amin, 2014; Lim, 2019; Oguntomisin \& Oladipo, 2017). Simplified text adverts attract the attention of subscribers, and thus the following hypothesis was formulated in this study:

$\mathbf{H}_{1}$ : Simplicity of bulk text advertising positively affects subscriber attention

\subsubsection{Frequency}

SMS advertising frequency was defined by Teixeira (2014) as the rate at which subscribers receive text advertisements. Hallgrimsson (2016) also contributes to that definition by adding time frames to her definition. According to Hallgrimsson (2016), SMS advertising frequency refers to the time intervals between two text adverts sent from the same advertising source going to the same subscriber.

Frequency of an advertisement also includes the perception of subscribers. Therefore, it is not only measured in quantitative terms, but also subjectively (Teixeira, 2014). For instance, some subscribers may receive one unsolicited SMS per day, and that could be too much for them, yet others might receive ten such messages in a day and they might not be affected.

The frequency at which unsolicited bulk SMSs are sent to customers has an impact on the attention of customers. According to Afzal, Paras, and Gangwani (2015), when customers have a perception that they are bombarded by too much SMSs from one source, their subliminal attention may lead to selective distortion. From consumer behaviour studies by Schiffman and Kanuk (2008), when such situations arise, consumers' absolute threshold and differential threshold are affected. That means that the difference between receiving an SMS and not receiving it becomes the same (no difference between something and nothing). Subscribers' level of sensation will be reduced. Giao and Vuong (2020) opine that mobile phone advertising should not be perceived as irritating by consumers, implying 
reasonable message dispatch by marketers.

Contrary to SMS overload, Gever and Olijo (2017) found out that if bulk SMSs are sent at the right time, to the right person, in the right format they yield better results in terms of customer attention and advert retention. The same result was found by Afzal, Paras, and Gangwani (2015) who see an SMS as a good medium of communication because it is personalized and can be referred to on a later date. Malikula (2020, p.67) therefore suggests that "text your idea to your subscriber when he is ready to hear about it, do not overstay your welcome but be short, precise and avoid repeating the same idea over and over again."

Frequency of SMS advertisements is high if consumers perceive that they receive many messages in a short space of time, if texts are displeasing, lag time is short and the quantity is too high (Gever \& Olijo, 2017; Hallgrimsson, 2016). High frequency reduces consumers' differential and absolute thresholds; thus the following hypothesis is presented:

$\mathbf{H}_{2}$ : Frequency of bulk text advertising inversely affects subscriber attention.

\subsubsection{Informativenes}

Almossawi (2014, p.58) defines SMS informativeness as "the ability of advertisement to inform consumers of product alternatives so that purchases yielding the greatest possible satisfaction can be made". Informativeness of SMS advertisements can also mean the ability of an SMS advert to successfully give related information in a manner that is understood by the subscriber. Mulilima (2020) reiterates that an effective SMS advert focusses on the ability of an SMS to inform the subscribers of the product's relevant qualities.

Literature shows that there exists a positive relationship between informativeness of the bulk SMS and several consumer-related variables (Brackett \& Carr, 2011; David, 2016; Giao \& Vuong, 2020; Lee, 2017). Almossawi (2014) noticed the relationship between informativeness and consumer attitudes towards SMS adverts. Dix, Jamieson, and Phau (2019) noticed the relationship of SMS informativeness and creation of awareness, whilst Malikula (2020) noticed an association between SMS informativeness and the AIDA model of advertising.

In the view of Dickinger and Haghirian (2004) SMS information services include news, weather, traffic, market rates, horoscopes, or songs. The receiver of the services would pay little or nothing for this relevant and personalized information. Such information buys the attention of the subscriber, making him notice the product that the company is advertising. Higher information quality perception of SMS adverts is typically yielded if accuracy, meaningfulness and timeliness of the information provided are ensured; since informativeness is reliant on the match between content provided by the mobile service and the subscriber's information requirements (Almossawi, 2014).

In line with Drossos et al. (2014), SMS advertising should be informative for it to gain subscribers' attention. An ambiguous message could easily be distorted in the customers' mind thereby contributing to spamming. Other informative bulk SMS advertisements include SMS promotions with clear prizes and information on how to participate (Drossos et al., 2014). Informativeness is linked to consumers' perceived value. If consumers perceive that the text message is informative and valuable, they are more likely to pay attention (Nguyen, 2020; Tran, 2020).

An informative text advert is newsworthy, entertains, has good product information and has up to date information (Drossos et al., 2014; Malikula, 2020; Mulilima, 2020). Thus, an informative text advert is more likely to capture the attention of consumers, hence the following proposition is stated:

H3: Informativeness of bulk text advertising positively affects subscriber attention.

\subsubsection{Credibility}

Dickinger and Haghirian (2004) define credibility as the extent to which consumers perceive claims made about the brand in the SMS advert to be truthful and believable. Preceding research has illustrated a positive correlation between the consumers' perception of bulk SMS advertisement's credibility value and consumer behaviour (Brackett \& Carr, 2011; David, 2016; Dickinger \& Haghirian, 2004; Drossos et al., 2014).

Credibility and corporate image are considered as the base of consumers' trust (Giao \& Vuong, 2020; Oh \& Park, 2020). Choi (2020) argues that credibility of a brand may be affected even by the scandals of organisational CEOs, and that affects consumers' intention to buy. The relationship between the consumer and the advertising brand is highly influenced by trust and it is a common finding that consumers in general do not trust advertising due to issues of false marketing efforts (Almossawi, 2014; Ambarwati et al., 2020; Cha \& Seo, 2019; Le \& Hoang, 2020).

Consumers reject bulk SMS advertisements that come from sources that are not credible. Strom, Vendel, and Bredican (2014) highlight that the problem of credibility in SMS advertising can be avoided in two basic ways. The first one is through building a strong brand that attracts loyalty of the customers. Once subscribers are more loyal to the brand that will heighten the credibility levels of the brand, because credibility is closely tied to trust. The more customers trust the advertising brand, the more they perceive it as credible.

The second attribute that SMS advertisers should be mindful of when advertising using bulk SMSs is to brand their SMSs (Strom et al., 2014). A message received without 
a clear print of the sender is likely to be rejected by customers. That means loss of attention and no action will be taken by the customers. Another contribution comes from Malikula (2020) who notes that subscribers are more receptive to SMSs that are branded.

Therefore, consumers perceive claims made about the brand in the SMS advert to be truthful and believable, and perceive the source to have knowledge and skills and to give truthful and unbiased information (Dickinger \& Haghirian, 2004; Strom et al., 2014). Credible messages are therefore ingredients of consumer attention and the study made the following hypothesis.

$\mathbf{H}_{4}$ : Credibility of bulk text advertising positively affects subscriber attention.

\subsection{The conceptual framework}

Consumers often do not deliberately pay attention to advertisements, and it is impossible to process all advertisement messages that are received (Haan \& MoragaGonzalez, 2011; Hooda \& Ankur, 2020). However, the more often (frequency) consumers are exposed to bulk SMS advertisements, the less likely that they pay attention and remember it, and the more likely that they selectively block it. At the same time, if consumers receive simple to understand SMSs (Simplicity), they are more likely to develop a keen interested and attention into the commercial. SMS commercials that are not credible and less informative are selectively distorted, leading to poor attention. It is against this background that the conceptual model in Figure 1 is presented.

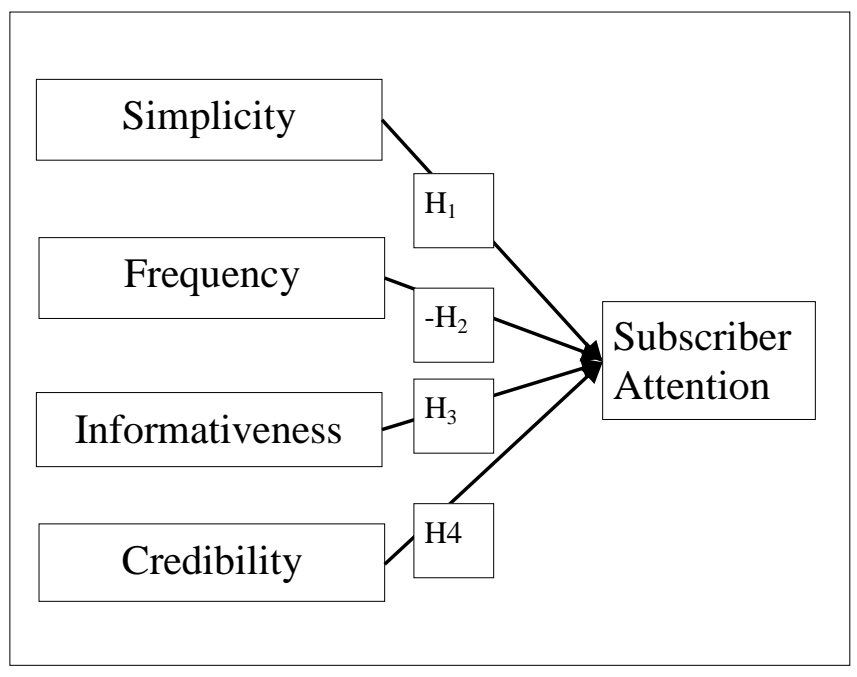

Figure 1: The Conceptual Framework

It was hypothesised that bulk text advertising's
Simplicity (S), Frequency (F), Informativeness (I) and Credibility (C) were direct influencers of Subscriber Attention (SA). Therefore, subscriber attention was said to be a function of the four bulk text advertising constructs (SFIC).

$$
\text { Hence } S A=f n{ }^{\Sigma}[S+F+I+C]
$$

\section{Research Methods and Materials}

A causal research design was used to determine the cause and effect relationship that existed between bulk text advertising and subscriber attention. The study followed a quantitative approach where quantifiable data was gathered using a structured questionnaire. The target population for the study was made up of all mobile telecommunications subscribers in Zimbabwe. The focus of the study was to identify the differential effects of SMS advertising on subscribers of Econet Wireless, Netone and Telecel. This brought up three distinct strata based on the telecommunication company which the respondents belonged to. Systematic random sampling was then employed to draw 293 valid responses from the sampling frame.

Only telecommunications subscribers were chosen as the target group because they were the ones who were exposed to bulk text advertising. Since text advertising uses mobile telephony, only active subscribers were ideal to offer meaningful and reliable responses to the study. These were the ones who were also affected by SMS advertisements since they were the recipients.

To ensure validity of the instrument, the development of the questionnaire closely followed the research objectives of the study. That helped the study to be internally valid. Face validity was ensured through a pilot test which was carried out to some Econet subscribers prior to the rolling out of the survey. Also the pilot study helped to rephrase other questions that were rather ambiguous for the respondents. External validity was achieved through administering the questionnaire to a large audience of respondents thereby allowing generalisation of findings to all subscribers.

\section{Results and Discussion}

\subsection{Data Profiling}

The response rate of the study was $76 \%$. The Cronbach Alpha Test was used to measure the reliability of the study variables and all variables had Cronbach Alpha coefficients above 0.78 .

Male respondents were predominantly many over female 
respondents, $59 \%$ were males whilst $41 \%$ were females. The majority of respondents $(66 \%)$ were drawn from the age category 18 to 30 years whilst the least represented age category was of young children below 18 years of age with a valid percent of $3.8 \%$. Therefore, it can be interpreted that people of all age groups in Zimbabwe have mobile telephone access, though most users are young adults.

The mean score for number of years which customers spent loyally with a service provider was rather high at 7 years and 6 months. This result means that consumers in the sampling frame had been exposed to bulk SMSs for a considerable amount of time which averages 7.5 years.

On average, respondents agreed that they received an average of 7 SMS advertisements per week (mean 6.74) from their service provider. Other subscribers actually indicate that they received as much as 9 SMSs from their telecommunication companies per week!

\subsection{The determinants of effective bulk text message advertising}

The study identified four determinants of effective bulk text message advertising namely simplicity, informativeness, credibility and frequency. These determinants were measured using a 5-point Likert scale which was coded from 1 (strongly disagree) through to 5 (strongly agree). The composite mean scores are thus shown in Table 1.

Of the four determinants of bulk text advertising, respondents indicated that credibility had the highest mean of 3.6 which aligns with the category 'agree' on the measuring instrument. That means that subscribers considered originators of SMSs to be credible. Subscribers also considered that SMSs they receive were fairly simple for their liking, with a mean simplicity score of 3.3, which falls in the 'neutral' category. Subscribers registered their disagreement to the rate at which they received bulk texts. A low frequency mean score of 1.9 shows that subscribers were not happy with the rate at which they were receiving bulk texts. A rather 'fair' mean score for informativeness determinant also signified that the extent to which SMSs were informative was lukewarm.

Table 1: Descriptive statistics of SMS Determinants

\begin{tabular}{|c|c|c|c|c|c|}
\hline & N & Min & Max & Mean & SD \\
\hline Simplicity & 293 & 1.80 & 4.20 & 3.308 & .8910 \\
\hline Frequency & 293 & 1.00 & 3.25 & 1.898 & .7912 \\
\hline Informativeness & 293 & 1.00 & 4.80 & 2.821 & 1.285 \\
\hline Credibility & 293 & 2.00 & 4.60 & 3.607 & .8938 \\
\hline ValidN(list wise) & 293 & & & & \\
\hline
\end{tabular}

\subsection{An analysis of the effect of bulk text messaging determinants on consumer attention}

To test the four study hypotheses, the study used Stepwise Regression and Correlation test statistics, whose results are in Table 2.

Table 2: Model Summary for Bulk SMS Advertising

\begin{tabular}{|c|c|c|c|c|c|c|}
\hline \multirow{2}{*}{ Model } & \multirow{2}{*}{$\mathbf{R}$} & $\mathbf{R}^{2}$ & \multirow{2}{*}{ Adjusted $\mathbf{R}^{2}$} & & \multicolumn{3}{|c|}{ Change Statistics } \\
\cline { 5 - 7 } & & & & $\mathbf{R}^{2}$ Change & F Change & Sig. F Change \\
\hline 1 & $.674^{\mathrm{a}}$ & .455 & .453 & .455 & 242.78 & .000 \\
\hline 2 & $.761^{\mathrm{b}}$ & .579 & .576 & .124 & 85.104 & .000 \\
\hline 3 & $.775^{\mathrm{c}}$ & .601 & .597 & .023 & 16.505 & .000 \\
\hline 4 & $.803^{\mathrm{d}}$ & .645 & .640 & .044 & 35.616 & .396 \\
\hline 5 & $.803^{\mathrm{e}}$ & .645 & .641 & .000 & & .530 \\
\hline
\end{tabular}

Note: ${ }^{\text {a. }}$ Predictors: (Constant), Credibility

b. Predictors: (Constant), Credibility, Frequency

c. Predictors: (Constant), Credibility, Frequency, Simplicity

d. Predictors: (Constant), Credibility, Frequency, Simplicity, Informativeness

e. Predictors: (Constant), Frequency, Simplicity, Informativeness

Table 2 presents the regression models' summary. Five models are presented with varied r-squared values. Model 5 with three independent variables (Frequency, Simplicity,
Informativeness) was adopted for analysis because it explains subscriber attention by the highest rate of $64 \%$ (adjusted $\mathrm{r} 2=0.641)$. Though the study found an 
insignificant R Squared change of 0.53 from Model 4 to Model 5, Model 5 was adopted because model 4 consist of one independent variable (Credibility) which was found to be statistically insignificant against subscriber attention as shown in Table 5.

Model 5 also shows a very strong and positive correlation between bulk text messaging determinants and subscriber attention, with a correlation coefficient of 0.803 . This means that if the variables of the model are enhanced, subscriber attention would be enhanced significantly.

To ascertain the level of significance of Model 5, Table 3 results were analysed.

Table 3 indicates that bulk text messaging for Model 5 was statistically significant. The p-value of Model 5 was 0.00 , with an F coefficient of 174.790 . Therefore, $p=0.000$ $<0.05$.

Table 4: The Correlations and Coefficients of the Study Model

\begin{tabular}{|c|c|c|c|c|c|c|c|}
\hline & \multirow{2}{*}{ Model } & \multicolumn{2}{|c|}{ Unstandardized Coefficients } & \multirow{2}{*}{$\begin{array}{c}\text { Standardized Coefficients } \\
\text { Beta }\end{array}$} & \multirow{2}{*}{$\mathbf{t}$} & \multirow{2}{*}{ Sig. } & \multirow{2}{*}{$\frac{\text { Correlations }}{\text { Zero-order }}$} \\
\hline & & B & Std. Error & & & & \\
\hline \multirow[b]{2}{*}{1} & (Constant) & 1.6 & .150 & & 10.9 & .00 & \\
\hline & Credibility & .63 & .040 & .674 & 15.6 & .00 & .674 \\
\hline \multirow{4}{*}{5} & (Constant) & 1.8 & .181 & & 10.2 & .00 & \\
\hline & Frequency & -.33 & .038 & -.314 & -8.6 & .00 & -.405 \\
\hline & Simplicity & .68 & .034 & .725 & 19.8 & .00 & .673 \\
\hline & Informativeness & .16 & .024 & .246 & 6.5 & .00 & .121 \\
\hline
\end{tabular}

Note : a. Dependent variable: subscriber attention

Table 4 shows the coefficients of the determinants of effective bulk text messaging and the level of significance for each determinant. The same table also shows the correlations of the independent variables against the dependent variable.

Simplicity Determinant had the highest correlation coefficient of 0.673 , which signifies a strong positive correlation with subscriber attention. It also had a beta coefficient of $0.725, \mathrm{~T}$ value of 19.76 and a statistically significant $p$ value of 0.000 . Thus, the study accepted the alternate hypothesis $\left(\mathrm{H}_{1}\right)$ and concluded that simplicity of text advertising positively affects subscriber attention. This means that if SMS adverts are made simple, short, precise, easy to read and understand; they are more likely to grab consumer attention at a larger scale.

This result was consistent with literature findings. For instance, Drossos et al. (2014) found out that, SMSs that are simple to understand, short in size and are written in simplest terms were more attractive than those with deeper words. Byun and Kyung (2020) also found related results in relation to mobile shopping apps, that ease to use applications influence purchase intention. However, though simplicity of a message buys consumer attention, the study by Ngwero (2019) concluded that SMSs should not just be
Table 3: Significance Level of the Study's Model

\begin{tabular}{|c|c|c|r|r|r|c|}
\hline \multicolumn{7}{|c|}{ ANOVA } \\
\hline \multicolumn{2}{|c|}{ Model } & $\begin{array}{l}\text { Sum of } \\
\text { Squares }\end{array}$ & df & $\begin{array}{c}\text { Mean } \\
\text { Square }\end{array}$ & F & Sig. \\
\hline \multirow{4}{*}{1} & Regression & 92.246 & 1 & 92.246 & 242.787 & $000^{\mathrm{b}}$ \\
\cline { 2 - 7 } & Residual & 110.564 & 291 & .380 & & \\
\cline { 2 - 7 } & Total & 202.809 & 292 & & & \\
\hline \multirow{4}{*}{5} & Regression & 130.749 & 3 & 43.583 & 174.790 & $000^{f}$ \\
\cline { 2 - 7 } & Residual & 72.060 & 289 & .249 & & \\
\cline { 2 - 7 } & Total & 202.809 & 292 & & & \\
\hline
\end{tabular}

Note: ${ }^{\text {a. }}$ Dependent Variable: Subscriber Attention

Predictors: (Constant), Frequency, Simplicity, Informativenes simple always. Farmers in Ngwero (2019)'s study preferred technical messages not just simplified messages.

Frequency Determinant was inversely correlated with consumer purchase attention $(\mathrm{r}=-0.41)$, with a low inverse impact on subscriber attention $(\beta=-0.31, \mathrm{~T}=-8.644, \mathrm{p}=$ $0.00)$. This shows that the association between frequency of SMS advertisements sent and subscriber attention was inverse and statistically significant with a relatively low impact. The study thus rejected the null hypothesis and concluded that frequency of text advertising inversely affects subscribers' attention $\left(\mathrm{H}_{2}\right)$. The results mean that when using bulk SMS advertising, the frequency of message dispatch should be kept to a minimum. The more frequent the text messages, the lower the consumer attention. Other scholars also confirmed that there is an inverse association between these two variables (Afzal et al., 2015; Amin, 2014; Tsang, 2014).

Informativeness Determinant explains subscriber attention by $25 \%(\beta=0.246, \mathrm{~T}=6.536)$; and the association was found to be statistically significant with a $\mathrm{p}$ value of 0.00 . The correlation between informativeness and subscriber attention was also very weak $(r=0.12)$. The study therefore rejected the null hypothesis and concluded that informativeness of text advertising positively affects 
subscribers' attention $\left(\mathrm{H}_{3}\right)$. These statistical results mean that when text messages are newsworthy, entertains, have good product information and have up to date information; consumers are more likely to pay attention to them. Therefore, companies ought to make their bulk SMS advertisements informative, not just to dispatch ambiguous and non-beneficial messages.

A study in Turkey by Ene and Ozkaya (2015) found related results. Ene and Ozkaya (2015) found out that perceived informativeness-amusingness had a positive effect on attitudes towards mobile advertisements, and suggested that SMS marketers must provide information that is useful for their subscribers.

Credibility Determinant was the fourth variable of the study's conceptual framework. The study however found out that the variable was excluded from the regression model because it was not statistically significantly explaining subscriber attention, as shown in Table 5.

Table 5: Insignificant variable excluded from the model

\begin{tabular}{|c|l|c|c|c|}
\hline \multicolumn{5}{|c|}{ Excluded Variables } \\
\hline 5 & Model & Beta In & t & Sig. \\
\hline & Credibility & $.064^{\mathrm{e}}$ & .629 & .530 \\
\hline
\end{tabular}

Note: ${ }^{\text {e. }}$ Predictors in the Model: (Constant), Frequency, Simplicity, Informativeness

Table 5 shows that for Model 5 , Credibility had a p-value of $0.53(\beta=0.064, \mathrm{~T}=0.629)$ which was insignificant. The study thus accepted the null hypotheses and concluded that credibility of bulk text advertising does not affect subscriber attention $\left(\mathrm{H}_{4}\right)$. This means that subscribers do not really matter where the message comes from, but are more worried about the frequency of messages sent, the simplicity of the message and the level of informativeness of the message.

This conclusion was rather divergent from other scholars who actually found a statistical significance (Brackett \& Carr, 2011; Ene \& Ozkaya, 2015). The variance is thus attributed to geographical variance.

\section{Conclusions}

Through literature analysis, the study identified four determinants of effective bulk text message advertising. These determinants are simplicity, frequency, informativeness and credibility. The study concluded that that SMS advertisements sent by telecommunication companies were simple for consumers to comprehend, they were dispatched too frequently for the liking of consumers, yet the quality of information in the adverts was regarded as relatively informative. The study also concluded that consumers view advertisement sources as credible.

The study further concluded that the determinants of effective bulk mobile advertising have a significant effect on consumer attention. The determinants predict consumer attention by $64 \%$. However, the study concluded that not all four determinants of the conceptual framework had a statistical significant effect on consumer attention. The credibility determinant had an insignificant effect. Therefore, the study concluded that credibility of the sender of text advertisement was not an aspect which affects the attention of consumers. Simplicity showed a higher positive impact on consumer attention whilst informativeness had the least positive impact. Only the frequency determinant recorded an inverse impact on consumer attention. Therefore, the study concluded that to grab subscribers' attention, bulk SMS advertisements should be dispatched less frequently, be very simple to understand and should be informative.

The study offers practical significance to the management and execution of bulk text message advertising. Marketers, and related managers, would find it valuable to understand the factors that improve their bulk text messaging campaigns. Therefore, using the study result, SMS marketing would be enhanced in the telecommunications industry, and other related industries. Customer attention would be improved thereby enriching absolute threshold and differential threshold of consumers. Customer satisfaction would improve as the friction between marketers and subscribers is minimized by the dissemination of informative text messages at the right time and in the simplest form.

At a time when researches on bulk text messaging are scant in Zimbabwe, this study contributes significantly to the existing academic body of knowledge in understanding the dynamics of mobile marketing in Zimbabwe. This will inform future methodologies of academic studies on the contextual issues in Zimbabwe. The presented model of study tested in this study will also act as benchmark for enhancing the effectiveness of bulk text messaging advertising the world over.

This study also has some limitations. First, the examination of the factors that enhance the effectiveness of bulk text messaging was only limited to four variables. However, there may be some other factors, besides the ones discussed in the study model, that influence the effectiveness of bulk SMS advertising. Second, this is the first time the variables of the study were empirically tested against consumer/ subscriber attention. The model may need to be tested in various situations to prove its integrity and validity.

Regardless of the existence of some limitations, the study significantly presented practical and statistically proven factors that improve the propensity of marketers to capture the attention of consumers using bulk text message advertising.

\section{References}

Afzal, S., Paras, G., \& Gangwani, S. (2015). An examination of 
determinants influencing consumer adoption of SMS: A perspective from youth of Pakistan. World Journal of Management, 6(1), 117-135.

Ajzen, I., \& Fishbein, M. (1983). The theory of planned behaviour, organisational behaviour and human decision processes. Journal of Theoretical and Applied Information Technology, 50(1), 179-211.

Almossawi, M. (2014). Effectiveness of SMS advertising. A study of young customers in Bahrain. Global Journal of Management and Business Research: E Marketing, 14(4), 5466.

Ambarwati, R., Astuti, M., \& Dijaya, R. (2020). Strengthening the intention to use vehicle tax service online in Indonesia. Journal of Distribution Science, 18(5), 25-33.

Amin, A. (2014). Mobile advertising effect on consumer behaviour. International Journal of Business, Economics and Environmental Management, 1(1), 12-26.

Angtha, R., \& Gastha, G. (2015). Factors influencing consumer willingness to accept mobile advertising. International Journal of Mobile Marketing, 2(1), 50-58.

Bhandari, R. S., \& Bansal, S. (2018). Prospects and challenges of social media marketing: study of Indian management institutes. East Asian Journal of Business Management, 8(4), 5-15.

Bomiegha, A., \& Ezema, K. (2017). Subscribers attitude towards unsolicited text messages (UTM) among Nigerian telecommunication firms. Journal of Business and Management, 19(10), 26-40.

Brackett, L., \& Carr, B. (2011). Cyberspace advertising vs other media: Consumer vs mature student attitudes. Journal of Advertising Research, 41(5), 23-32.

Byun, S., \& Kyung, M. (2020). Effects of the attributes of mobile shopping apps on purchase intention of fashion products. Journal of Industrial Distribution \& Business, 11(1), 49-57.

Cha, S., \& Seo, B. (2019). The effect of brand trust of home meal replacement on repurchasing in online shopping. Journal of Business, Economics and Environmental Studies, 9(3), 21-26.

Chaparadza, A. (2018). ZANU-PF sends new unsolicited bulk text messages; they even refer to the recent demonstrations by MDC. Retrieved March 15 2020, from https://www.techzim.co.zw/2018/07/zanu-pf-sends-newunsolicited-bulk-text-messages-they-even-refer-to-the-recentdemonstrations-by-mdc.

Cho, B., Potluri, R., \& Youn, M. (2020). A study on the effect of product recommendation system on customer satisfaction: focused on the online shopping mall. Journal of Industrial Distribution \& Business, 11(2), 17-23.

Choi, J. (2020). The influence of CEO's scandal on consumers' product purchase. Journal of Industrial Distribution \& Business, 11(4), 47-56.

Choi, N., Liu, H., \& Li, Z. (2018). The effects of Chinese consumers' self-construal and advertising type on brand attitude. East Asian Journal of Business Management, 8(3), 33-41.

David, J. X. (2016). The influence of personalization in affecting consumer attitudes toward mobile advertising in China. Information Systems Journal, 47(2), 69-79.

Dickinger, A., \& Haghirian, P. (2004). An investigation and conceptual model of SMS marketing. Proceedings of the 37th Hawaii International Conference on System Sciences (pp.14-
26). Big Island, Manoa: Institute of Electrical Electronics Engineers.

Dix, S., Jamieson, K., \& Phau, I. (2019). Drivers of SMS advertising acceptance. International Journal of Marketing Management, 2(6), 56-88.

Drossos, D., Giaglis, G. M., Lekakos, G., Kokkinaki, F., \& Stavraki, M. (2014). Determinants of effective SMS advertising: An experimental study. Journal of Interactive Advertising, 4(2), 88-96.

Ene, S., \& Ozkaya, B. (2015). The role of mobile advertising on consumers' purchase decisions: A research on consumer attitudes towards mobile advertising. International Journal of Humanities and Social Science, 5(1), 235-248.

Enpocket, E. (2016). Consumers perception of advertising clutter and its impact on consumer behaviour. Journal of Advertising Research, 38(1), 29-40.

Gever, C. V., \& Olijo., I. I. (2017). Testing the AIDA model hypothesis vis-à-vis subscribers' response to unsolicited SMS adverts. International Journal of Communication, 5(2), 19-34.

Giao, H. N., \& Vuong, B. N. (2020). Vietnamese consumer attitudes towards smartphone advertising. Journal of Asian Finance, Economics and Business, 7(5), 195-204.

Godin, S. (2004). Permission marketing: Turning strangers into friends and friends into customers. New York, NY: Simon and Schuster Ltd.

Gondoiri, G. (2018). The impact of mobile phone marketing on consumer behaviour. International Journal of Social Studies, 4(3), 101-113.

Haan, M. A., \& Moraga-Gonz_alez, J. (2011). Advertising for attention in a consumer search model. The Economic Journal, 12(1), 552-579.

Hallgrimsson, A. G. (2016). Factors affecting attitudes and behavioural intentions towards in app mobile advertisements: A cross cultural comparison between India and the United Kingdom. Global Journal of Management and Business Research, 4(3), 106-118.

Hidayat, S., Pabuayon, I. M., \& Muawanah, U. (2020). Marketing practices and value-added fish product in east Indonesia. Journal of Business, Economics and Environmental Studies, 10(2), 33-41.

Hooda, A., \& Ankur, A. (2018). Acceptance of social media as a marketing tool: A quantitative study. East Asian Journal of Business Management, 8(3), 5-12.

Johnson, J. P. (2014). The simple economics of advertising, marketing and product design. American Economic Review, 96(3), 756-84.

Jong, J., \& Lee, Y. (2017). Hybrid spam filtering for mobile communication. Computer and Security, 29(4), 446-459.

Karlsson, L. (2017). Advertising theories and models how well can these be transferred from text into reality? (Master's dissertation). University of Halmstad, Halland, Sweden.

Lai, L. (2014). The impact on mobile marketing on consumer behaviour. The Journal of Social Sciences and Humanities in Emerging Economies, 6(4), 76-85.

Lakhwani, M., Dastane, O., Satar, N., \& Johari, Z. (2020). The impact of technology adoption on organizational productivity. Journal of Industrial Distribution \& Business, 11(4), 7-18.

Le, H. B., Ngo, C. T., Trinh, T. T., \& Nguyen, T. T. (2020). Factors affecting customers' decision to use mobile banking service: A 
case of Thanh Hoa province, Vietnam. Journal of Asian Finance, Economics and Business, 7(2), 205-212.

Le, N. B., \& Hoang, T. P. (2020). Measuring trusts and the effects on the consumers' buying behavior. Journal of Distribution Science, 18(3), 5-14.

Lee, M. (2020). An empirical study of the Korean telecommunication market and iot smart home: effects of bundling strategy on consumers' responses. Journal of Distribution Science, 18(5), 15-23.

Lim, A. (2019). The effects of mode vividness in mobile advertising when presented in the context of consumer goals and product involvement (Doctoral dissertation). University of Canterbury, Christchurch, New Zealand.

Malikula, S. (2020). Acceptance of mobile advertisement on consumer behaviour. International Journal of Humanities \& Social Science Studies. 3(4), 186-194.

Mulilima., H. (2020). Mobile marketing and its value for consumers and retailers. Journal of Business and Social Sciences, 4(2), 54-77.

Nguyen, O. T. (2020). Factors affecting the intention to use digital banking in Vietnam. Journal of Asian Finance, Economics and Business, 7(3), 303-310.

Ngwero, N. (2019). Value-added services in mobile commerce: An analytical framework and empirical findings from a national consumer survey. Journal of African Sciences and Business, 3(1), 46-57.

Oguntomisin, V., \& Oladipo, H. (2017). Assessment of acceptability of unsolicited mobile advertisements among Nigerian students. International Journal of Humanities \& Social Science Studies, 3(4), 46-66.
Oh, A., \& Park, H. (2020). Marketing strategies for improving customer attitude using airline advertising model: Focusing on corporate image and brand loyalty. Journal of Distribution Science, 18(4), 13-26.

Oh, W., \& Lee, W. (2020). A study on the opt-in marketing. Journal of Industrial Distribution \& Business, 11(2), 49-59.

Pikirayi, T. (2017). How Econet ruined my SMS experience. Retrieved March 15 2020, from https://www.techzim.co.zw/2017/11/how-econet-ruined-mysms-experience/.

Ryu, J. S. (2019). Consumer characteristics and shopping for fashion in the omni-channel retail environment. Journal of Business, Economics and Environmental Studies, 9(4), 15-22.

Schiffman, L. G., \& Kanuk, L. L. (2008). Consumer behaviour ( $9^{\text {th }}$ Edition). Upper Saddle River, NJ: Prentice Hall.

Strom, S., Vendel, E., \& Bredican, B. (2014). Effect of short message service (SMS) as a complementary marketing communications instrument. Journal of Advertising Research, 46(2), 209-216.

Teixeira, T. S. (2014). The rising cost of consumer attention: Why you should care, and what you can do about it. (Doctoral dissertation). Harvard Business School, Boston, Massachusetts.

Tran, V. D. (2020). Assessing the effects of service quality, experience value, relationship quality on behavioral intentions. Journal of Asian Finance, Economics and Business, 7(3), 167175.

Tsang, M. M. (2014). Consumer attitudes toward mobile advertising: An empirical study. International Journal of Electronic Commerce, 2(3), 65-78. 